\title{
Recent Studies on Supra-Threshold Auditory Processing Deficits
}

\author{
Inyong Choi \\ Department of Communication Sciences and Disorders, University of lowa, lowa, IA, USA
}

\section{역치상 청각 기능 장애에 관한 최신 지견}

최 인 용

아이오와주립대학교 의사소통장애학과

\begin{abstract}
Many normal-hearing listeners, as well as the majority of hearing impaired listeners, complain of the difficulties associated with communicating in social settings. In clinics, we see marked individual differences in speech-in-noise understanding that are not predicted by individuals' hearing thresholds. We consider the listeners who show consistently poor performance in the speech intelligibility and/or speech-in-noise tasks, even without elevated hearing thresholds. "Central auditory processing disorder (CAPD)" has been used as an umbrella term that indicates such supra-threshold hearing problems. However, we still do not know which "central" mechanisms contribute to such problems with auditory processing. This review will introduce recent studies that substantially enhanced our understanding on neurological substrates of such central auditory processing deficits. Those studies revealed two common sources of the central hearing deficits, neither of which is closely related to hearing threshold in normal-hearing listeners: 1) differences in the fidelity of subcortical encoding of supra-threshold sound, and 2) differences in the efficacy of top-down executive control in directing selective attention. Behavioral and neuroimaging studies in both categories will be introduced. The reviewed studies would define key systems and mechanisms for central auditory processing for communications in noisy environments and neuroimaging correlates of their disorders.
\end{abstract}

Key Words: Supra-threshold auditory processing, Cochlear neuropathy, Sensory gain control, Functional neuroimaging.

Received: February 28, 2016 / Accepted: March 10, 2016

Correspondence: Inyong Choi, Department of Communication Sciences and Disorders, University of lowa, 250 Hawkins Dr, lowa City, IA 52241, USA

Tel: +1-319-335-8725 / Fax: +1-515-294-4111 / E-mail: inyong-choi@uiowa.edu

\section{INTRODUCTION}

청각 역치 수준이 정상임에도 소리를 통한 의사소통에 장애 가 있는 모든 경우를 통틀어 청각처리 장애(Cooper, 1991; Griffiths, 2002; Moore, 2013)라고 일컬어왔으나, 최근 '역치상 청각 장애(supra-threshold hearing deficit), 혹은 ‘숨겨진 청력 소실(hidden hearing loss)'이라는 용어가 대두되고 있다 (Liberman, 2015). 본 종설에서는 이를 통틀어 '역치상 청각 기 능 장애(supra-threshold auditory processing deficits)'로 칭하 고자 한다. 즉 '역치상 청각 기능 장애’란 기존의 순음 역치 검 사(pure-tone threshold test)로 진단할 수 없는 모든 종류의 청 각적 장애를 일컫는다. 이 환자들은 소음 환경에서 말소리를 인 지하는 일이나, 원하는 음성에 선택적으로 주의(attention)를 집중하는 일에 특히 어려움을 호소한다(Choi et al., 2014;
Ruggles \& Bharadwaj, 2011). 최근 연구에 따르면 미국의 경우 청각적 어려움으로 병원을 찾는 인구의 약 10 퍼센트는 역치 레 벨이 정상인 것으로 밝혀지는 등(Hind et al., 2011; Kumar et al., 2007; Lin et al., 2011) 역치상 청각 기능 장애가 더욱 심각 해지고 있으나 이를 진단할 표준화된 방법이 존재하지 않으며, 이에 따라 이를 보조하기 위한 의료기기나 재활 방법 또한 마 련되어있지 않다.

최근 동물 생리학 연구 결과가 누적되고 기능적 신경 영상 기술이 청각 처리 연구에 활발히 사용되면서 역치상 청각 기능 장애의 신경학적 기제가 밝혀지고 있다. 최근의 연구는 크게 두 가지 흐름을 보인다. 첫번째 부류의 연구는 말단 청각기관 및 뇌간 단계의 신경활동이 소리의 물리적 형질을 얼마나 정확하 게 부호화하는지, 그리고 그 부호화의 정확도가 소음 노출이나 노화에 의해 어떻게 열화하는지를 규명한다. 두번째 부류의 연 
구는 청각 피질 및 그 이후의 대뇌 피질 단계의 소리 정보 처리 에 주목한다. 중요한 소리는 크게, 덜 중요한 소리 및 잡음은 작 게 부호화하는 '감각 이득값 조절(Hillyard et al., 1998)' 기능의 신경학적 기제와 해당 기능의 개인차 및 결손이 이 두번째 부 류의 주된 연구 주제다. 본 종설은 두 분야의 연구를 모두 소개 하며, 이를 통해 역치상 청각 기능 장애의 다양한 원인을 이해 하고 그간 연구 결과의 임상적 의의를 조명하고자 한다.

\section{Degraded fidelity in subcortical auditory encoding}

강한 소음에 노출될 경우 일시적으로 역치 레벨이 상승하는 것은 잘 알려진 청각 현상이다. 이 후 역치 레벨은 소음 노출 이 전으로 회복되고는 하는데, 최근까지도 이는 말초 신경 손상이 회복된 증거로 생각되었다. 그러나 최근의 동물 생리학 연구는 이에 반하는 결과를 보인다. 즉 강한 소음에 노출된 후 상승했 던 역치 레벨이 회복된 이후에도 구심성(afferent) 청신경에 영 구한 손상이 발생한 것이 관찰되었다(Kujawa \& Liberman, 2009). 해당 연구의 저자는 이처럼 영구적인 역치 상승을 수반 하지 않는 와우각 신경병질(cochlear neuropathy)이 널리 관찰 되는 현상이며, 이러한 '숨겨진' 신경 손상이 소음 환경에서의 어음 인지, 이명(tinnitus), 청각 과민(hyperacusis) 등으로 연결 될 수 있다 주장한다.

여기서 와우각 신경병질은 내유모세포에 연결된 청신경의 결 손을 일컫는데, 또다른 연구는 특히 낮은 자발적 발화율(low spontaneous firing rate)을 가지는 청신경이 높은 자발적 발화 율을 가지는 청신경에 비해 노화 및 소음 노출에 의해 보다 잘 손상되는 것을 보였다(Lin et al., 2011; Furman et al., 2013). 낮은 자발적 발화율을 가지는 청신경의 경우 보다 강한 음압의 소리까지 선형적인 형태의 반응 함수를 보이며, 즉 대체로 높은 음압 상태에서의 시간적 포락선(temporal envelope) 변화 등을 분별하는데 중요한 역할을 하는 것으로 여겨진다. 최근의 연구 는 소음 노출 빈도가 높은 피험자가 진폭 변조(amplitude modulated) 협대역 잡음(narrowband noise)에 대해 더 미미한 복잡 청각 뇌간 반응(complex auditory brainstem response)을 보이며, 행동 실험에서도 이러한 피험자의 진폭 변조 검출 (modulation detection) 및 음원 국재화(sound source localization) 능력이 열화된 것을 보였다(Ruggles et al., 2011; Ruggles et al., 2012; Bharadwaj et al., 2015). 이러한 연구 결과는 와우각 신경병질이 어떠한 형태의 지각적 결손을 유발하는지 암시한다.

\section{Poor efficacy in the top-down control of cortical auditory processing}

청성 유발 전위(auditory evoked potential)를 이용하면 소리
에 대한 청각 피질(auditory cortex)의 반응을 관찰할 수 있다. 지난 세기의 연구 결과는 소리에 대한 선택적 주의가 청성 유 발 전위 중 N1 반응의 크기를 크게 변화시키는 것을 보였다 (Hillyard, 1973; Woldorff, 1993; Choi et al., 2013) (Figure 1). 즉 물리적으로 동일한 소리에 대한 N1 반응이 해당 소리에 주 의를 기울인 경우 더 커지고, 반대로 해당 소리를 무시한 경우 더 작아진다(Figure 1a). 이러한 감각 이득값 조절(sensory gain control, Hillyard et al., 1998)은 소음 환경에서 표적 음원 만을 선택해 듣는 능력의 기제로 생각되었다.

최근의 연구는 이러한 감각 이득값 조절의 범위에 큰 개인차 가 있음을 보인다(Choi et al., 2013, Figure 1b, c 참조). 그리고 감각 이득값 조절이 미미한 피험자의 경우, 즉 주의를 기울인 소 리에 대한 N1 반응 크기와 주의를 기울이지 않은 소리에 대한 $\mathrm{N} 1$ 반응의 크기 차이가 적은 피험자의 경우 소음 환경에서의 어음 분별 능력이 떨어지는 것이 관찰되었다(Choi et al., 2014).

기능적 신경 영상기법을 이용해 선택적 주의 시의 대뇌 피질 활동을 관찰한 또 다른 연구들은 이러한 청각적 작업에 두정엽 하구 및 전전두엽의 시각 정보 처리 영역이 함께 관여함을 보인 다(Goldberg et al., 2014; Huang et al., 2014; Kong et al., 2014; Weisz et al., 2014; Michalka et al., 2015). 한편 전쟁 참 전 후 외상후 스트레스에 의한 뇌손상(traumatic brain injury) 을 입은 환자들이 정상적인 역치 레벨을 가지고 있음에도 소음 환경에서의 어음 인지에 어려움을 호소하며, 해당 환자들의 감

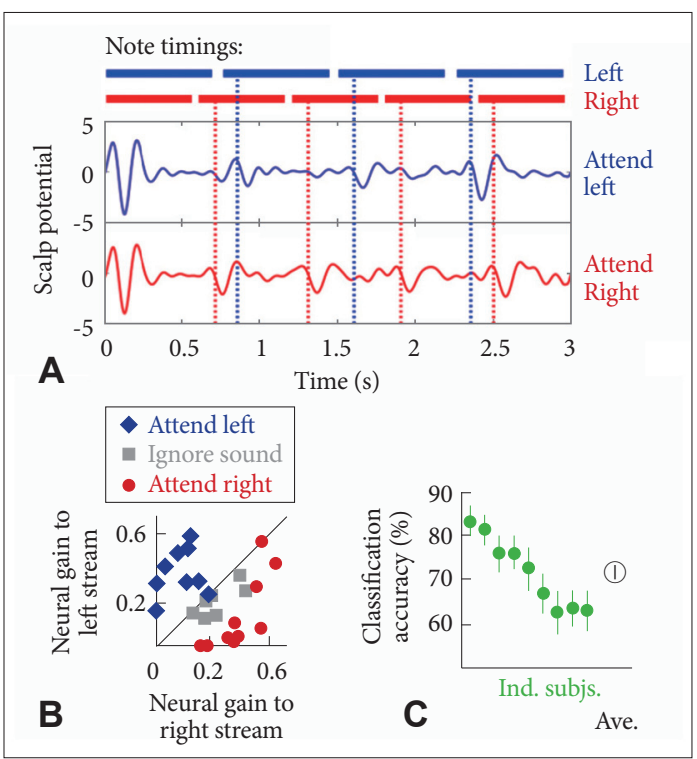

Figure 1. Attention modulates event-related N1 responses. A: Two competing melodies have different note onsets (top). For the same stimuli, onsets in the attended, but not the ignored stream, elicit N1 (compare top and bottom across-subject average plots). B: N1 magnitudes from left and right streams reflect which stream is attended (each point, one subject). C: Classification of attentional focus using individual trials is better than chance $(50 \%)$ for all listeners, but shows individual differences. Adapted from Choi et al., 2013. 
각 이득값 조절 범위가 대조군에 비해 유의미하게 작은 것이 보고되었다(Bressler et al., 2014). 이러한 연구는 대뇌 전반에 걸친 손상이나 병변이 역치상 청각 기능에 장애를 유발할 수 있음을 시사한다.

\section{DISCUSSIONS}

말초 청각기관(peripheral auditory system)으로부터 뇌간 (brainstem)을 거쳐 대뇌피질(cerebral cortex)까지 이어지는 청 각 전달 경로의 모든 단계에서 청각 처리의 장애가 발생할 수 있다. 그러나 청각 역치(threshold) 기반의 기존 청력검사는 주 로 말초 청각기관 손상에 의한 청력 소실만을 진단한다. 그러나 정상적인 청각역치를 가지고 있음에도 청각적 어려움을 호소하 는 환자, 즉 ‘숨겨진 청력소실’ 환자가 증가하고 있으며, 이 환자 들은 소음 환경에서 말소리를 인지와 선택적 주의(selective attention)에 특히 어려움을 호소한다. 최근의 연구는 소음 노출 및 노화에 의한 와우각 신경병질, 그리고 각종 뇌신경 손상이 나 병변에 의한 청각 피질의 감각 이득값 조절의 실패가 위와 같은 역치상 청각 처리 장애의 원인일 수 있음을 보인다. 기능 적 자기공명영상 및 뇌전도 등 기능적 신경 영상 기술이 역치 상 청각 기능 장애의 진단에 이용될 수 있으며, 이에 관한 임상 적 연구 및 검증이 요구된다.

중심 단어 : 역치상 청각 기능 장애·와우각 신경병질·감각 이득 조절·기능적 신경 영상.

\section{REFERENCES}

Bharadwaj, H. M., Masud, S., Mehraei, G., Verhulst, S., \& Shinn-Cunningham, B. G. (2015). Individual differences reveal correlates of hidden hearing deficits. The Journal of Neuroscience, 35(5), 2161-2172.

Bressler, S., Bharadwaj, H., Choi, I., Bogdanova, Y., \& Shinn-Cunningham, B. G. (2014). 32nd annual symposium of national neurotrauma society: Auditory selective attention impairments in blast-exposed veterans with traumatic brain injury. San Francisco, CA.

Choi, I., Rajaram, S., Varghese, L. A., \& Shinn-Cunningham, B. G. (2013). Quantifying attentional modulation of auditory-evoked cortical responses from single-trial electroencephalography. Frontiers in Human Neuroscience, 7, 1-19.

Choi, I., Wang, L., Bharadwaj, H., \& Shinn-Cunningham, B. (2014). Individual differences in the attentional modulation of cortical responses correlate with selective attention performance. Hearing Research, 314, 10-19.

Cooper, J. C. Jr. \& Gates, G. A. (1991). Hearing in the elderly-the framingham cohort, 1983-1985: Part II. prevalence of central auditory processing disorders. Ear and Hearing, 12(5), 304-311.

Furman, A. C., Kujawa, S. G., \& Libermann, M. C. (2013). Noise-induced cochlear neuropathy is selective for fibers with low spontaneous rates. Journal of Neurophysiology, 110(3), 577-586.
Goldberg, H. R., Choi, I., Bharadwaj, H. M., \& Shinn-Cunningham, B. G. (2014). Auditory attention in a dynamic scene: behavioral and electrophysiological correlates. The Journal of the Acoustical Society of America, 135(4), 2415-2415.

Griffiths, T. D. (2002). Central auditory processing disorders. Current Opinion in Neurology, 15(1), 31-33.

Hillyard, S. A., Hink, R. F., Schwent, V. L., \& Picton, T. W. (1973). Electrical signs of selective attention in the human brain. Science. 182, 17780.

Hillyard, S. A., Vogel, E. K., \& Luck, S. J. (1998). Sensory gain control (amplification) as a mechanism of selective attention: electrophysiological and neuroimaging evidence. Philosophical Transactions of the Royal Society of London Biological Sciences, 353, 1257-1270.

Hind, S. E., Haines-Bazrafshan, R., Benton, C. L., Brassington, W., Towle, B., \& Moore, D. R. (2011). Prevalence of clinical referrals having hearing thresholds within normal limits. International Journal of Audiology, 50(10), 708-716.

Huang, S., Chang, W. T., Belliveau, J. W., Hämäläinen, M., \& Ahveninen, J. (2014). Lateralized parietotemporal oscillatory phase synchronization during auditory selective attention. Neuroimage, 86, 461-469.

Kong, L., Michalka, S. W., Rosen, M. L., Sheremata, S. L., Swisher, J. D., Shinn-Cunningham, et al. (2014). Auditory spatial attention representations in the human cerebral cortex. Cerebral Cortex, 24(3), 773-784.

Kujawa S. G. \& Liberman, M. C. (2009). Adding insult to injury: cochlear nerve degeneration after "temporary" noise-induced hearing loss. The Journal of Neuroscience, 29(45), 14077-14085.

Kumar, G., Amen, F., \& Roy, D. (2007). Normal hearing tests: is a further appointment really necessary? Journal of the Royal Society of Medicine, 100(2), 66-66.

Liberman, M. C. (2015). Hidden hearing loss. Scientific American, 313(2), 48-53.

Lin, F. R., Niparko, J. K., \& Ferrucci, L. (2011). Hearing loss prevalence in the United States. Archives of Internal Medicine, 171(20), 1851.

Lin, H. W., Furman, A. C., Kujawa, S. G., \& Liberman, M. C. (2011). Primary neural degeneration in the guinea pig cochlea after reversible noise-induced threshold shift. Journal of the Association for Research in Otolaryngology, 12(5), 605-616.

Michalka, S. W., Kong, L., Rosen, M. L., Shinn-Cunningham, B. G., \& Somers, D. C. (2015). Short-term memory for space and time flexibly recruit complementary sensory-biased frontal lobe attention Networks. Neuron, 87(4), 882-892.

Moore, D. R., Rosenb, S., Bamiouc, D. E., Campbelld, N. G., \& Sirimannae, T. (2013). Evolving concepts of developmental auditory processing disorder (APD): a British society of audiology APD special interest group 'white paper'. International Journal of Audiology, 52(1), 3-13.

Ruggles, D. \& Shinn-Cunningham, B. (2011). Spatial selective auditory attention in the presence of reverberant energy: individual differences in normal-hearing listeners. Journal of the Association for Research in Otolaryngology, 12(3), 395-405.

Ruggles, D., Bharadwaj, H., \& Shinn-Cunningham, B. (2012). Why middleaged listeners have trouble hearing in everyday settings. Current Biology, 22, 1417-1422.

Weisz, N., Müller, N., Jatzev, S., \& Bertrand, O. (2014). Oscillatory alpha modulations in right auditory regions reflect the validity of acoustic cues in an auditory spatial attention task. Cerebral Cortex, 24(10), 25792590.

Woldorff, M. G., Gallen, C. C., Hampson, S. A., Hillyard, S. A., Pantev, C., Sobel, D., et al. (1993). Modulation of early sensory processing in human auditory cortex during auditory selective attention. Proceedings of the National Academy of Sciences, 90(18), 8722-8726. 